\title{
Ensino de Filosofia: tendências e desafios
}

Sílvio Gallo

professor livre-docente da Faculdade de Educação da Unicamp

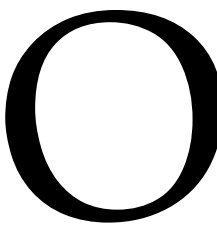

debate em torno do ensino de Filosofia no Brasil, especialmente na educação média, não é novo. Estudos esparsos e pontuais, embora em número bastante reduzido, podem ser encontrados ao longo da história da educação no país, notadamente no século $X X$, depois da criação da Universidade de São Paulo e de seu Departamento de Filosofia. É, porém, no final da década de 1970 e, sobretudo, durante a década de 1980, que a discussão ganha vulto, mediante a articulação dos Departamentos de Filosofia das universidades brasileiras em torno de uma mobilização para exigir do governo militar a "volta" da disciplina aos currículos da educação média, então denominada segundo grau. Como sabemos, a reforma educacional levada a cabo pelo regime militar por meio da Lei $\mathrm{n}^{\mathrm{o}}$ 5.692/71 tirou do segundo grau essa disciplina, a qual deixou de figurar tanto na chamada "parte comum" quanto na "parte diversificada" dos currículos desse nível de ensino.

O movimento foi intenso: encontros de professores e de estudantes de Filosofia; publicação de artigos a favor e contrários a seu ensino na educação média; publicação de livros; manifestações e articulações políticas. Com isso, já ao final da década de 1980 começamos a ver despontar, em Programas de Pós-graduação em

Filosofia e Educação - ISSN 1984-9605 - v. 4, no 1 - abril-setembro de 2012 
Educação, dissertações de mestrado focadas nesse tema. Porém, seria demais afirmarmos a existência de um campo de pesquisas sobre ensino de Filosofia, naquele momento.

Com a publicação da Lei de Diretrizes e Bases da Educação Nacional em 1996 (Lei no 9394/96), de acordo com a qual os estudantes do que passou a ser denominado Ensino Médio deveriam dominar "conteúdos de Filosofia necessários ao exercício da cidadania", o debate acadêmico ganhou força. Desde o final da década de 1990 temos assistido a diversos encontros e congressos focados no tema. Destaco, dentre outros, a realização, na Universidade Metodista de Piracicaba, em 2000, do Congresso Brasileiro de Professores de Filosofia e, a partir de 2001, a realização dos Simpósios Sul-Brasileiros sobre Ensino de Filosofia, pela importância que tiveram e têm tido ${ }^{1}$. Na esteira da agitação dos eventos acadêmicos, vieram a publicação de livros, e mesmo de coleções específicas sobre ensino de Filosofia $^{2}$, a publicação de artigos e a intensificação das pesquisas acadêmicas em nível de

1. Os Simpósios Sul-brasileiros são realizados pelo Fórum de Coordenadores dos Cursos de Filosofia da Região Sul. O primeiro foi realizado em Passo Fundo/RS, em paralelo ao III Encontro dos Cursos de Filosofia do Sul do Brasil. A princípio, os simpósios eram anuais, passando a ser bienais. No Congresso Brasileiro de 2000 tirou-se como diretriz a realização de encontros por região; dessa forma, houve simpósios nas regiões Sudeste, Centro-oeste e Norte-nordeste - nenhum deles, porém, com a mesma continuidade observada pelos encontros da região Sul. Destaque-se que em dezembro de 2012 acontecerá, na Universidade Federal de Pernambuco, o $2^{\underline{o}}$ Congresso Brasileiro de Professores de Filosofia, retomando os debates propostos em 2000 .

2. Apenas para citar algumas: Coleção Filosofia e Ensino, da Ed. Unijuí; Coleção Filosofia na Escola, Ed. Vozes; Coleção Filosofar é Preciso, Ed. Loyola.

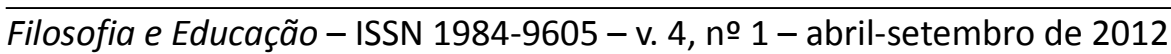


mestrado e de doutorado. Com isso, pensamos ser possível dizer que foi se constituindo no país um campo de estudos e pesquisas sobre ensino de Filosofia, que foi se consolidando ao longo da última década. Hoje, contamos já com uma produção bastante significativa na área, que mais recentemente recebeu um reforço importante com a criação do PIBID (Programa Institucional de Bolsas de Iniciação à Docência), ao qual muitos cursos de Filosofia têm aderido, com relevantes resultados.

No contexto deste campo de investigações, o Departamento de Filosofia e História da Educação da Faculdade de Educação da Universidade Estadual de Campinas foi um dos pioneiros, ao criar sua Linha de Pesquisa Ensino de Filosofia, no PAIDEIA - Grupo de Estudos e Pesquisas em Filosofia e Educação. Decisiva, para a criação da linha, foi a constatação da existência de vários trabalhos nessa área, seja em nível de Mestrado, seja de Doutorado, além dos estudos realizados nesse campo por vários professores do grupo. Desde então, a linha articulou e consolidou as pesquisas sobre ensino de Filosofia na Unicamp, com a produção de diversos trabalhos, nos mais distintos níveis, sob os mais diferentes enfoques.

É nesse quadro histórico e conceitual, articulando uma problemática contemporânea, que Filosofia e Educação apresenta o presente dossiê temático sobre Ensino de Filosofia, organizado com a cooperação dos professores que integram a referida linha de pesquisa: Lidia Maria Rodrigo, Renê José Trentin Silveira e Roberto Goto. Pesquisadores brasileiros e estrangeiros foram convidados a

Filosofia e Educação - ISSN 1984-9605 - v. 4, no 1 - abril-setembro de 2012 
apresentar suas produções sobre o tema, expondo assim um panorama amplo das tendências do que se está pesquisando nesse campo.

Abrimos o dossiê com o artigo L'enseignement de la philosophie dans les lycées en France: les enjeux contemporaines, de Hubert Vincent, professor na Université de Rouen, na França, que se dedica à Filosofia da Educação e à formação de professores de Filosofia. O artigo é a versão original da palestra apresentada por Vincent durante o II SIMPHILO - II Simpósio Sobre Ensino de Filosofia -, realizado na Faculdade de Educação da Unicamp entre 09 e 11 de dezembro de 2009. Em seu artigo, o autor aborda a tradição do ensino de Filosofia na França, abordagem que implica tanto a problematização de sua realidade contemporânea quanto a exposição dos princípios que fundamentam uma transmissão da Filosofia, relativa não apenas aos saberes produzidos ao longo do tempo mas também à transmissão de um "aprender a pensar". Dirigindo-se a "estrangeiros", Vincent procura explicitar os pressupostos do ensino da Filosofia em seu país, com a certeza de que com isso causará um grande estranhamento, o qual deflagra o desafio de fazer pensar sobre nossa própria experiência com ensino da Filosofia no Brasil.

A transmissibilidade da Filosofia é o que, por seu turno, questiona Laura Galazzi, professora na Universidade de Buenos Aires e doutoranda em Filosofia na mesma instituição. Seu artigo, $L a$ explicación en la enseñanza de la filosofía: la búsqueda de un devenir menor, toma por base as teses de Rancière em O Mestre Ignorante - cinco

Filosofia e Educação - ISSN 1984-9605 - v. 4, no 1 - abril-setembro de 2012 
lições de emancipação intelectual e sua crítica a uma sociedade pedagogizada, centrada na lógica da explicação. Contrapondo-se a tal lógica, que coloca o ensino de Filosofia numa perspectiva de transmissão hierárquica e centrada no saber, a autora busca na ideia de uma literatura menor, em Deleuze e Guattari, uma via para pensar a explicação dos conceitos filosóficos em sala de aula de uma outra maneira, que possa ser emancipatória.

No mesmo campo conceitual localiza-se o texto seguinte, Repensando o lugar da representação, da transmissão e da experiência no ensino da Filosofia. Escrito por Rodrigo Gelamo, professor da UnespMarília e por Amanda Veloso Garcia, estudante na mesma instituição, o artigo parte de uma problematização do Programa São Paulo Faz Escola, que a Secretaria Estadual de Educação desenvolve desde 2008, fazendo uma análise crítica do material didático produzido para as aulas de Filosofia. A lógica da transmissão também é pensada a partir de Rancière e, em diálogo com Deleuze, ensaia-se a possibilidade de pensar um ensino que não seja representacional.

Os dois artigos seguintes, por acaso provenientes de uma mesma instituição, tratam de propostas de como ver e praticar o ensino da Filosofia no nível médio. Em As características do educador: uma leitura nietzschiana à luz de "Schopenhauer como Educador" Márcio Danelon, professor da Faculdade de Educação da Universidade Federal de Uberlândia, desenvolve uma reflexão sobre o ensino de Filosofia centrando-se na leitura do conhecido texto de Nietzsche, na

Filosofia e Educação - ISSN 1984-9605 - v. 4, no 1 - abril-setembro de 2012 
qual esse ensino se apresentará como uma formação para a vida, uma educação contra seu tempo, sendo o professor uma espécie de filósofo educador. Já em Educar para a vida: a formação filosófica na perspectiva da filosofia da práxis, Ana Maria Said e Gigliola Mendes, ambas do Instituto de Filosofia da Universidade Federal de Uberlândia, expõem e defendem uma proposta de ensino da Filosofia fundamentada na filosofia da práxis de Antonio Gramsci. O mesmo tema de uma formação para a vida aparece, mas, à diferença do que se lê em Nietzsche, trata-se aqui de uma educação centrada no conhecimento formalizado, visando não apenas à constituição do indivíduo autônomo, mas a toda uma transformação social.

Em A Filosofia no Ensino Médio: a favor da "Filosofia que chega depois" Wilson Correia (Centro de Formação de Professores da Universidade Federal do Recôncavo Baiano) e Sílvio Gallo (Faculdade de Educação da Unicamp) tematizam a "segunda chegada" da Filosofia aos currículos, mediante o conceito de endereçamento curricular. A Filosofia que "chega primeiro" é aquela enunciada na LDB de 1996, uma Filosofia endereçada para a cidadania. A Filosofia que "chega depois" é a que aparece a partir de 2006, por determinação do Conselho Nacional de Educação, e em 2008, quando se institui a obrigatoriedade de seu ensino por lei federal. Para os autores, essa segunda chegada possibilita que o ensino da disciplina se dê numa circunstância harmônica com o próprio fazer filosófico, estando nos currículos de uma maneira que 
não seja uma "traição" aos princípios da Filosofia, como poderia fazer crer sua primeira chegada, subordinada à cidadania.

Américo Grisotto, professor do Departamento de Filosofia da Universidade Estadual de Londrina, assina o artigo Ensino Médio: manuais voltados para o ensino de Filosofia. Trata-se do resultado de um extenso e exaustivo estudo que fez o autor, mapeando os manuais didáticos para ensino de Filosofia disponíveis no mercado editorial brasileiro. Assinala Grisotto, porém, que não se trata de uma simples exposição do que está disponível, mas de um mapeamento de intencionalidades, de diferentes maneiras de pensar a Filosofia, o que implica distintas estratégias para seu ensino.

Encerrando o dossiê, retoma-se a questão relativa ao papel e ao lugar do texto filosófico nas aulas de Filosofia no Ensino Médio com o artigo de Geraldo Balduino Horn e Rui Valese, ambos vinculados à Universidade Federal do Paraná. Os autores discutem a referida questão no contexto da formação do professor de Filosofia na UFPR, avaliando a influência das Diretrizes Curriculares na estruturação do ensino de Filosofia no Paraná e analisando a produção editorial voltada para os alunos do Ensino Médio, na qual se destaca o Livro Didático Público de Filosofia fornecido pela Secretaria de Educação. Concluem que a consciência crítica perseguida na e pela leitura de textos filosóficos deve produzir-se mediante a "reflexão da própria experiência vivida em confronto com a cultura".

Este número de Filosofia e Educação é constituído por outros três textos, encaminhados espontaneamente pelos autores. Na seção

Filosofia e Educação - ISSN 1984-9605 - v. 4, no 1 - abril-setembro de 2012 
Artigos, Bruno Henrique Uchôa, doutorando em Filosofia pela Universidade Federal de Santa Catarina, analisa as diretrizes epistemológicas da Filosofia Analítica como possíveis fundamentos para a educação, por exemplo, para pensar o currículo. Segundo o autor, essa linha de pensamento ficou ofuscada em Filosofia da Educação, dada a prevalência da perspectiva pragmatista de Dewey, sendo, pois, necessário resgatá-la. Em De Deus à Diferença: trajetória das matrizes filosóficas na educação brasileira, Cristiane Maria Marinho, professora da Universidade Estadual do Ceará, descortina um amplo panorama das matrizes filosóficas que nortearam a educação brasileira, desde a ação dos jesuítas e seus influxos no Brasil Colônia até os atuais debates em torno da diferença na educação, balizados pela filosofia de Gilles Deleuze.

Finalmente, na seção Experiências, com $A$ construção de um projeto coletivo na perspectiva da pedagogia histórico-crítica, Mara Peixoto Pessoa, Roberta Negrão de Araújo e Aparecido de Sampaio Baptista relatam a trajetória do Colégio Estadual Cristo Rei - Ensino Normal, relato no qual a pedagogia histórico-crítica proposta e desenvolvida por Dermeval Saviani desempenha o triplo papel de baliza teórica, de diretriz da práxis educativa e de objeto de análise e avaliação, na medida em que foi adotada por mais de um governo, no Estado do Paraná, como referência e coordenada de suas políticas educacionais.

Como se pode perceber, a presente edição de Filosofia $e$ Educação lança à pública luz, na perspectiva do pluralismo sustentado e pautado por sua política editorial, textos de autores de

Filosofia e Educação - ISSN 1984-9605 - v. 4, no 1 - abril-setembro de 2012 
variada proveniência, do Brasil e do Exterior, sobretudo de diferentes tendências filosóficas, de correntes de pensamento diversas, dando assim sua contribuição para o debate amplo e aprofundado sobre a educação brasileira, notadamente no que respeita ao ensino de Filosofia.

Filosofia e Educação - ISSN 1984-9605 - v. 4, no 1 - abril-setembro de 2012 